\title{
Correlation of Surface Geophysical and Logging Data of Some Selected Boreholes in Imo State, South Eastern Nigeria
}

\author{
Nwachukwu P. C. ${ }^{1}$, Okoro B. C. ${ }^{2}$, Osuagwu J. C. ${ }^{2} \&$ Nwankwo S. I. ${ }^{3}$ \\ ${ }^{1}$ Erosion Centre, Federal University of Technology, Owerri \\ ${ }^{2}$ Department of Civil Engineering, Federal University of Technology, Owerri \\ ${ }^{3}$ Department of Architecture, Abia State University, Uturu, Nigeria \\ Correspondence: David Wolf II, School of Management, Northern Canada University, Toronto, ON., M3A 2K7, \\ Canada. Tel: 1-613-947-3592. E-mail: davidwolf@gc.ca
}

Received: April 1, 2015

Accepted: November 5, 2015

Online Published: November 26, 2015

doi:10.5539/jgg.v7n4p1

URL: http://dx.doi.org/10.5539/jgg.v7n4p1

\begin{abstract}
Boreholes have become a major source of water supply in South Eastern Nigeria, an area with diversity in geology, topography and climatic conditions. The common approaches in borehole investigations are surface survey and logging. The two approaches are supposed to be complementary. However, for small schemes of groundwater development, logging is hardly considered.. Six boreholes were selected from locations at the three geographical zones of Imo state. The selected locations are Umueze, Umuduru, Ogbor-Ugiiri, Ngor Okpuala and Eziama. Geophysical survey and logging were carried out. Electrical resistivity method was adapted for geophysical survey. ABEM Terrameter (SAS) 300B with digital read-out was used for logging. The degree of correlation between the variables was determined by computing the coefficient of correlation denoted as $\mathrm{R}^{2}$. The results indicate generally poor correlations between logging and geophysical surface values for the selected boreholes except for the one located at Ngor Okpala with $\mathrm{R}^{2}$ value of 0.7408 . At this location, geophysical surface method for borehole locations can be carried without any Logging exercise to establish the Total Drilling Depth (TDD). This will help reduce the total cost for the drilling of the boreholes and also save time and much desired energy. In those areas where no correlation exists, there is need for Government Financial support in drilling sustainable borehloes as much costs are involved in investigation and construction works.
\end{abstract}

Keywords: geology, boreholes, correlation, geophysical, logging, Imo State

\section{Introduction}

Groundwater is subsurface water that fill voids in soils and permeable, geological formation or groups of formations with yield water in sufficient quantity to be of consequence source of supply is called aquifer. Groundwater accounts for over $95 \%$ of the earth's unable fresh water resources. It is uniquely suited as drinking water and it is widely disturbed. Over half of the World's population depends on ground water for drinking water supplies (Magaji, 1990). Nigeria has abundant groundwater resources which have been developed through shallow dug wells and boreholes. $60 \%$ of Nigerians depend upon groundwater for their water supply be it for domestic, industrial or agricultural use. Since 1980, there has been astronomical increase in the number of boreholes constructed in Nigeria by the Government, communities, individuals and Non-governmental organizations assisted by international organizations such as UNICEF, UNDP, EU, FAO and World Bank. There has thus been an over exploitation of groundwater. Water levels in boreholes have fallen and borehole fields have drastically declined over the years (Ofodile, 1992).

Most water wells are located, drilled and tested without the aid of professional Hydro geologists or water Engineers. Investigations and exploration contribute substantially to the cost of groundwater as a source of water supply. The cost of scientifically based studies is relatively high for small schemes. Geologic information can commonly give positive guidance for the location of wells, thus avoiding the expensive cost of unsuccessful wells. Proper well locations, however, is but one of a number a problems facing the perspective well owners, poor water quality, biological contaminations, future lowering of water levels in wells, and improper completion methods are some of the many problems dealt with frequently by hydrogeologists (Hess, 1986). However a major disadvantage is that abstraction is always through boreholes requiring constant pumping with attendant 
problems and quantity is hardly sufficient for large community water supply.

The common approaches in investigation are the surface survey and logging. Survey investigates the sub surface complexity of the site in respect of lithology and recommends total drill depth based on the prospective aquifer unit identified (NWR, 1991). The two approaches are supposed to be complementary. However, for small schemes of groundwater development, logging is never conserved.

Geologic measurements in boreholes provide useful information about surface aquifer but the heterogeneity of some prospective zones of the aquifer pose the real challenge in conventional well logging. Borehole geophysics presents several tools that may be applied to these fundamental problems. Although borehole geophysical logging is a common technique in the characterization of aquifers are difficult to describe using data obtained in a limited number of boreholes. The logs provide defined information about formation properties in the immediate vicinity of boreholes. However, one can never expect to drill enough boreholes to characterize aquifer flow systems on the basis of borehole data alone.

Imo state, an area with regional geographical variations is located in south-eastern Nigeria. The great diversity in geology, topography, and climate conditions in the three geographic zones (Owerri, Orlu, and Okigwe) would result in the variations in occurrences of groundwater. It is therefore important to correlate geophysical and logging data.

Among the most useful application of all geographical techniques, however, are in the interpretation of geologic structures and stratigraphy, thus eliminating the need of an expensive and extensive drilling program (Oyebande, 1984). For the six locations above, geophysical survey and logging were carried out. The main objective was to establish a standard and sustainable basis for proper borehole locations and design in the various zones.

\section{Methods}

Six locations in Imo state of Nigeria were selected for study. They are:

(i) Umueze, Ehime-Mbano L.G.A.

(ii) Umuduru, Amaike Mbieri, Mbaitoli L.G.A.

(iii) Umueziala-Umunna-Onuimo L.G.A.

(iv) Ogbor-Ugiiri Isiala Mbano L.G.A.

(v) Ngor Okpuala L.G.A

(vi) Eziama-Oru west L.G.A.

The subsurface geology of the project sites fall within the Benin formation, but associated with the transition area of Benin to Lignite formation. The lithology consists predominantly of coastal sediments, essentially sand, sand stone and minor clay. The underlying formation consists essentially of mudstone, and clay and lignite series.

The success of geophysical work depends on simple but distinct variations of density, electrical conductivity, magnetic susceptibility, electrical potential, elasticity and other measurable physical properties of the earth. Some physical methods measure directly the presence of subsurface water, while others do not. For the six locations above, geophysical survey and logging were carried out.

Electrical resistivity method was adapted for geophysical survey. It is based on the principle that the distribution of electrical potential in the ground around a current-carrying electrode depends on the electrical resistivities and distribution of the surrounding soils and rocks. (Whitmen et al, 2003) An electric current was passed through between a pair of electrodes and the drop in potential measured by an inner pair of electrodes. Since water increases the conductivity of soil or rock, the presence of groundwater was indicated by a decrease in resistivity. Thus, if the distribution of the electrical resistance in the subsoil is known, conclusions could be drawn concerning the thickness and depth to the interfaces of the subsurface layers.

The apparent depths and resistance of stratified subsoil were determined by vertical electric sounding (VES). The Schlumberger Array Configuration technique was used. The potential gradient at the midpoint of the spread was measured.Through the current electrodes $(\mathrm{AB})$ current was introduced into the ground. The current electrodes were spread much further apart at a predetermined distance than the potential electrodes.

The apparent resistivity $\mathrm{p}$ was computed from the relationship (Whitmen et al, 2003)

$$
p=\frac{2 \pi k V}{I}
$$


Where $\mathrm{I}=$ Current, $\mathrm{V}=$ potential difference, $\mathrm{k}=$ geometric factor which a function of electrode arrangement. Near surface geological structure was differentiated from the more deep-seated by employing more than one electrodes spacing during profiling. The variations in spacing was achieved by repeated traversing of the array along a distance between the electrodes and increased successively along the traverses until sufficient data were acquired. Low resistivity values are indicators of layer containing considerable amount of water. Lateral resistivity variations may hinder accurate interpretation of sounding data. Besides, depending on the minimum electrodes spacing used, narrow productive fracture zone electromagnetic traversing should be the method to get better results.

ABEM Terrameter (SAS) 300B with digital read-out was used for logging. The Terrameter system consists of a basic until called the terrameter SAS 300B which can be supplemented as desired with the SAS 300B booster and SAS log 200. SAS stands for signal Averaging system, a method whereby consecutive readings are taken automatically and the operator is satisfied with the stability of the result. SAS results are more reliable than those obtained using single-shot system. The logging exercise lasted for three hours, during which the self-potential (SP) and resistivity logs were run. The dependent variable (logging) was plotted against the Independent (geophysical surface) variable. Surface geophysical values cover depths from $(0-60 \mathrm{~m})$ or dry surface level of the borehole to the prospective (sand stone) water table layers, for all the considered boreholes.

The degree of correlation between the variables was determined by computing the coefficient of correlation (product moment denoted as R defined by the formula (Nwaogazie,1999)

$$
R^{2} \quad=\quad \frac{\sum\left(y_{e s t}-y\right)^{2}}{\sum(y-y)^{2}}
$$

Where $y=$ observed / actual values of the dependent variable

$$
\mathrm{y}=\text { mean value of } \mathrm{y}
$$

$\mathrm{y}_{\text {est }}=$ estimated value of $\mathrm{y}$ from a regression equation for a given value of the independent variable $\mathrm{x}$.

\section{Results}

Data collected from field studies and studies by Goeprobe (2011) were subjected to comprehensive analysis. For five locations; Umueze, Umuduru, Ogbor-Ugiiri ,Ngor Okpuala and Eziama, the geology fall under the Benin formation, consisting predominantly of coastal sediments, essentially sand, sand stone, silt stone and minor clay lenses. On the other hand, Umuduru area falls under Ogwashi - Asaba formation (Lignite formation). The base of Benin formation in most cases represents the base of the Aquifer prospective unit.

Electrical resistivity values for both the surface geophysical and logging exercises at specific drilling depths of the boreholes were recorded. Figures 1-5, present correralation plots of Logging and Surface geophysical values. For the geophysical, values cover depth $0-60 \mathrm{~m}$ or dry surface level of the borehole to the perspective (Sand stone) water table layers, for all the considered boreholes.

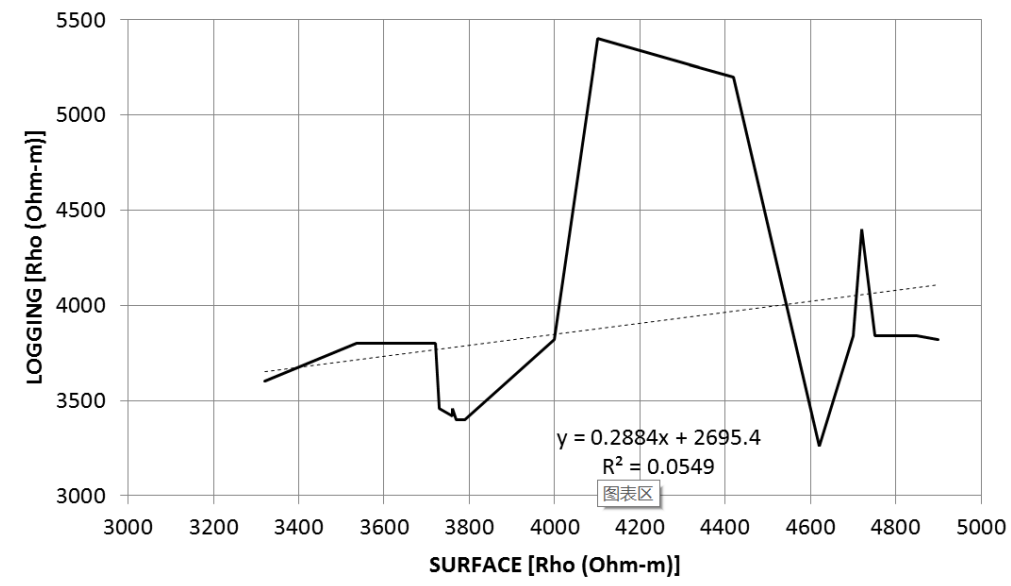

Figure 1. Logging and Geophysical Data plots; Umueze 1 


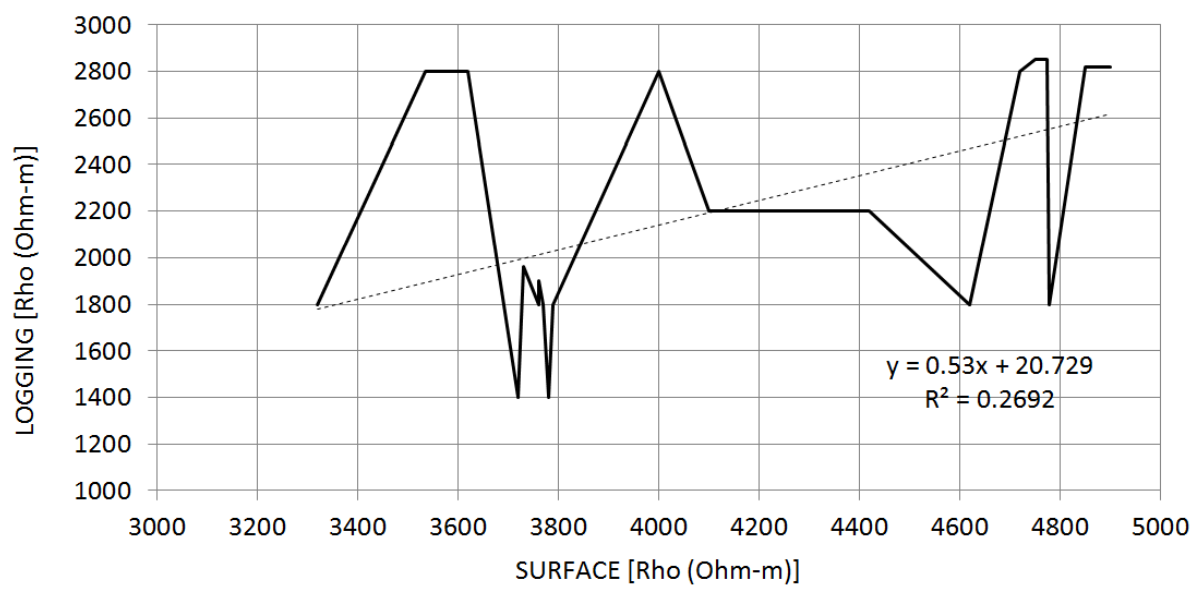

Figure 2. Logging and Geophysical Data plots; Umuezeala Umuna

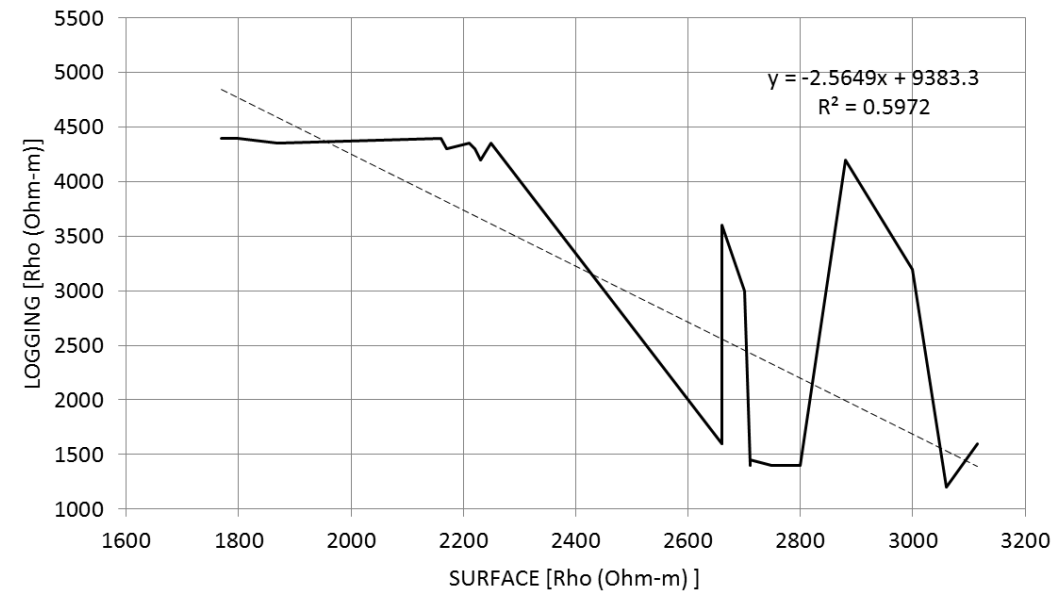

Figure 3. Logging and Geophysical Data plots; Ogbor Ugiri

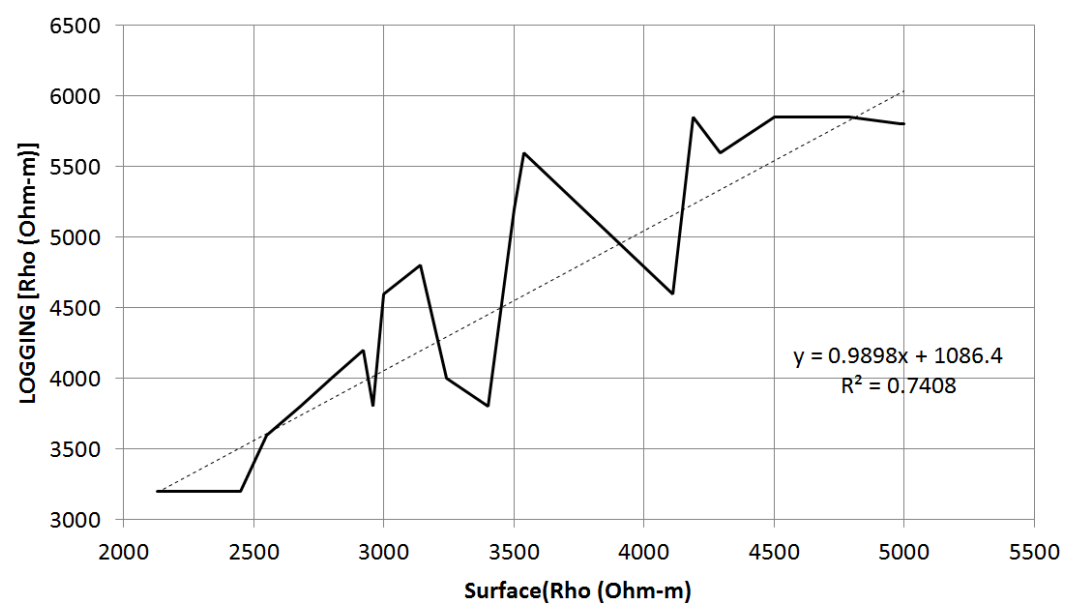

Figure 4. Logging and Geophysical Data plots; Ngor-Okpala 


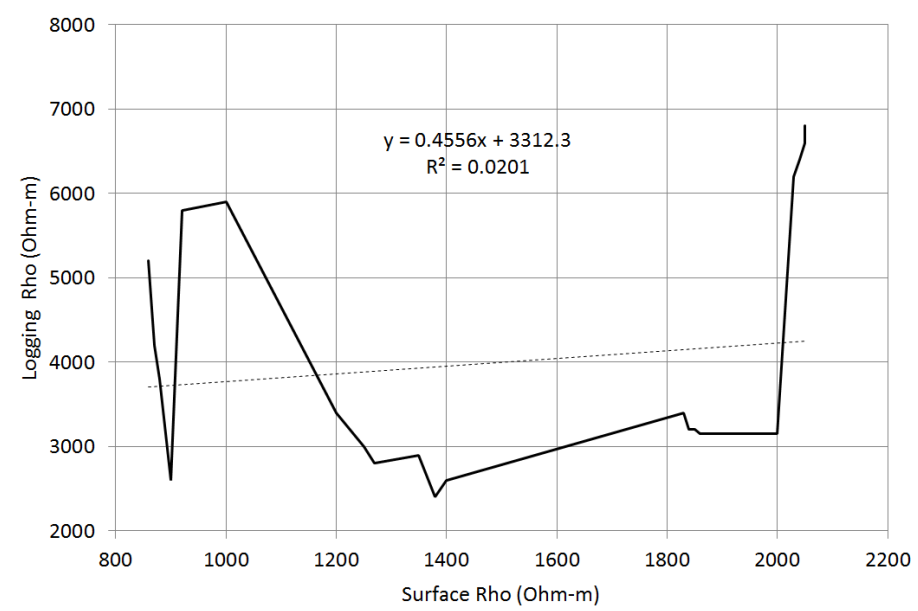

Figure 5. Logging and Geophysical Data plots; Eziama Ubulu

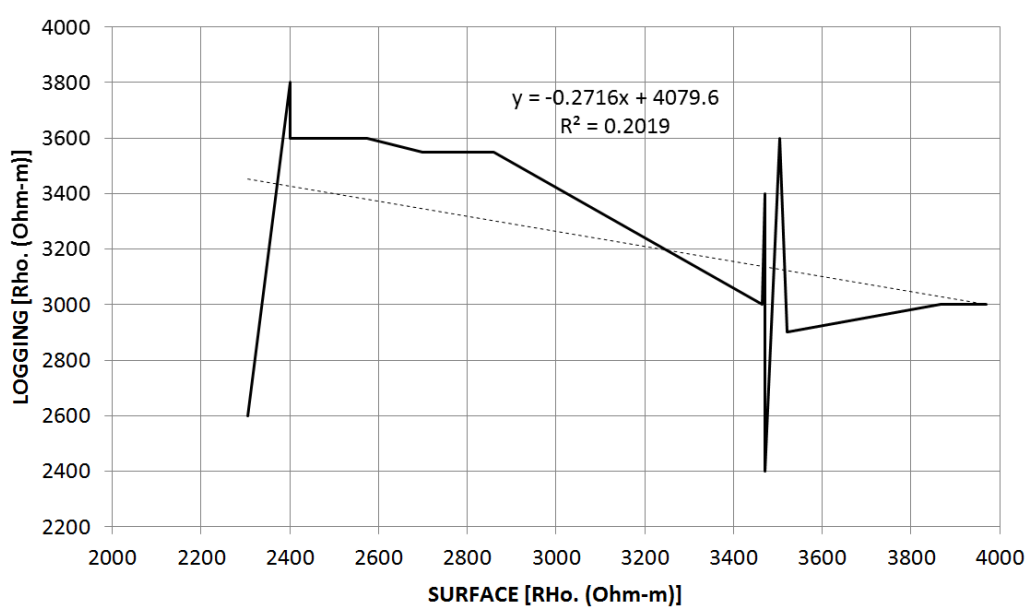

Figure 6. Logging and Geophysical Data plots; Umuduru- Amaike

\section{Discussions}

The study has attempted to identify the possibility of the existence of correlations between the logging and geophysical surface values of selected boreholes from the three geopolitical zones in Imo state south Eastern Nigeria

For any form of correlation to exist between the two chosen variables (logging and geophysical survey values) the values of $\mathrm{R}^{2}$ should be between 0.5 and 1.0. Computed values of $\mathrm{R}^{2}$ are $0.001,0.2692,0.592,0.7408,0.0201$ and 0.2019 respectively for Umueze, Umuezeala, Ogbor-Ugiri, Ngor Okpuala, Eziama-Ubulu and Umuduru respectively. Except for the one located at Ngor Okpala with $\mathrm{R}^{2}$ value of 0.7408 , these results indicate generally poor correlations between the variables. Geophysical surface method for borehole locations can thus be carried without any logging exercise in order to establish the Total Drilling Depth (TDD) at Ngor Okpuala area. This will help reduce the total cost for the drilling of the boreholes and also save time and much desired energy. In those areas where no correlation exists, there is need for Government Financial support in drilling sustainable borehloes as much costs would be involved in investigation and construction works. The recommended depths for drilling or TDD must be reached irrespective of any technical or operational difficulty except for geological factors.

\section{Acknowledgements}

We appreciate the former acting Vice- chancellor, Federal University of Teccnology Owerri, Prof. B.A. Nwachukwu for guiding us through this study. Special thanks to Geo Probe International consultants for assisting us with field data on boreholes in Imo state. We acknowledge the efforts of V.Ndu for helping in typpe-setting the manuscript. Finally,we acknowledge the contributions of the entire acsdemic staff of Civil 
Engineering Department of Federal University of Teccnology Owerri towards the succees of this study.

\section{References}

Geo Probe Consultants International Ltd. (2011). Surface Geophysical Logging Results of Boreholes in Imo state. Owerri.

Hess, A. E. (1986). Identifying Hydraulically Conductive Fractures with a slow-velocity Borehole Flow meter. Canadian Geotechnical Journal, 23(1), 69-78.

Magaji, A. A. (1990). Water for Sustainable Development. Paper presented at Water 90 Workshop on the role of Water in National Development, NWRI, Kaduna.

National Water Resources. (1991). Geophysical Investigations at Bobi, Banji, Kumbashi, Ubeji and Kaboji Niger State. Report submitted to the Federal Ministry of Water Resources, Abuja.

Nwaogazie, I. L. (1999). Probability and Statistics for Science and Engineering Practice. Print Konsults. Lagos.

Ofodile, M. E. (1992). Aspects of the Hydrogeological characteristics of the Sand stone Aquifer of the Lafia sub-basin of the middle Benue, Nigeria. Journal of Mining and Geology, 19, 162-188.

Oyebande, L. (1984). Regionalized Rainfall intensity-Duration frequency Relationship for planning and Engineering Designs. Prc. $1^{\text {st }}$ Biennial National Hydrology Symposium, Nigerian National Committee of International Hydrological Programme (IHP) Maiduguri, 335.

Whitman, W. E., Jalinoos, F., Sirles, P., \& Hanna, K. (2003). Application of Geophysical Methods to Highway related Problems. Federal Highway Administration. FHWA-IF-04-021.

\section{Copyrights}

Copyright for this article is retained by the author(s), with first publication rights granted to the journal.

This is an open-access article distributed under the terms and conditions of the Creative Commons Attribution license (http://creativecommons.org/licenses/by/3.0/). 